\title{
Insurance as a risk management system in green construction
}

\author{
Kheda Murtazova ${ }^{1, *}$, and Salambek Aliyev ${ }^{2}$ \\ ${ }^{1}$ Chechen State University named after A.A. Kadyrov, Grozny, Russian Federation \\ ${ }^{2}$ Grozny State Oil Technical University named after Academician M.D. Millionshchikova, Grozny, \\ Russian Federation
}

\begin{abstract}
The study of the problems of the impact of climate change on economic development has become in recent years one of the main directions of economic research. At the same time, along with the development of a global macroeconomic policy in the field of climate and green building, more and more attention is paid to the analysis of corporate strategies to reduce risks and adapt to the consequences of climate change. Without large-scale business investments in green innovative technologies and the introduction of corporate standards for reducing greenhouse gas emissions, it is impossible to achieve long-term targets for reducing global climate risks.
\end{abstract}

\section{Introduction}

Many major companies participate in the discussion of the problem of climate change, inform about plans to reduce greenhouse gas emissions in volumes that exceed the established limits, as well as achieve the status of a "carbon neutral company", talk about the priority of introducing "green" technologies in their products and business processes. More than 1,500 of the largest companies include a section on greenhouse gas emissions in their annual sustainability reports [3].

Despite the lack of an unambiguous definition and classification in the specialized literature, green technologies include a wide class of innovations aimed at reducing the negative impact on the environment in such areas as renewable energy, construction of new and reconstruction of existing buildings and other industries.

The growing economic attractiveness of new green technologies is evidenced by the growth of investments in this sector.

Buildings account for a significant part of the world's consumption of resources: $40 \%$ of energy, $30 \%$ of raw materials and materials, $25 \%$ of water and $12 \%$ of land resources, about $30 \%$ of global greenhouse gas emissions. Therefore, the use of green technologies in the construction of new and modernization of existing buildings is most often viewed by companies as a tool for managing climate risks, energy and resource conservation.

Construction is one of the most capital-intensive and organizationally complex sectors of the economy. This causes a high degree of risk for all participants in the construction

\footnotetext{
*Corresponding author: fu.ggni@mail.ru
} 
services market, who may face not only objectively determined risks associated with the complexity and duration of the production cycle, but also with the dishonesty of contractors and potential partners [1-2].

The risks accompanying each stage of construction from the project to the commissioning of facilities are varied and are usually measured in significant amounts. In addition, recently from the side of financial institutions and banks to ensure the protection of the financial resources they provide, the requirements for compulsory insurance of construction risks have been put forward, which requires building a system of relationships that takes into account the interests of all participants in the construction process.

In Russia, insurance of construction and assembly risks is not compulsory, and despite the emerging trend of growth in insurance contracts in this industry, it lags far behind world practice.

Since it is completely impossible to avoid risks, a scientifically grounded approach to risk management in the implementation of investment projects is required, which will allow, on the basis of the developed algorithm, to identify the level of uncertainty and minimize the negative impact of risk on the activities of the organization. All this necessitates ensuring economic protection of all participants involved in the construction and investment process from possible risks.

\section{Materials and Methods}

Investment activity is a prerequisite for the development and competitiveness of Russian construction enterprises, since construction is the most capital-intensive sector of the economy. It traditionally involves design and engineering organizations, uses expensive technologies and unique equipment, and concludes large supply contracts. It is obvious that the risks inherent in each stage of the project are varied and significant, and the possible losses during its implementation can be measured in huge amounts. Insurance of construction risks as part of the construction investment process at all its stages from the development of a feasibility study to the commissioning of the facility allows participants to compensate for unforeseen losses incurred during construction and provides protection for investment in construction [4].

The construction area in all countries is considered a high-risk area where there is a high probability of unfavorable and unpredictable situations during the implementation of an investment project (an increase in investment costs, a decrease in profits, etc.). In investment and construction activities (ISD), research, identification and identification of risk factors underlies the effective implementation of the economic interests and needs of all stakeholders. The study of risk management problems in the context of political, economic and regulatory transformations of the basic rules of doing business in the construction industry is one of the most difficult economic problems and provides the following main approaches: avoidance, prevention, insurance, transfer and acceptance of risk [5].

Unfortunately, as world and domestic practice shows, despite significant efforts to reduce risk (introduction of new standards, use of innovative technologies), when carrying out construction and installation works (CMP), the developer often faces the problem of situations that are difficult to predict and can lead to to an increase in construction time due to damage or loss of building materials, construction equipment, equipment during installation and installation, property of third parties, damage to life and health of people, and there is also a risk of a significant increase in the cost of objects from the initial investment amount [6].

Analysis of existing classifications of risks in relation to the investment and construction sector and an attempt to create on the basis of this classification a unified long- 
term methodology for increasing the efficiency of investment resources of construction organizations remains unrealized. As a rule, these techniques are aimed at solving specific tactical problems. The reasons for the occurrence and the degree of influence on investment activities for each risk is individual.

The most optimal solution in the context of analyzing the objectively evolving situation and taking into account the economic interests of IUD participants is the insurance of construction and installation risks. In this case, there is no need to accumulate funds on the accounts of the reserve fund to cover possible damage and the contractor can use these funds as working capital, in addition, the terms of restoration of the object can be significantly reduced by compensating the insurer for additional costs associated with the urgent delivery of building materials, equipment and overtime [7].

Construction and installation insurance is a real guarantee of ensuring economic protection of project participants from losses caused as a result of various types of dangerous situations. Unlike other types of property insurance, insurance of construction risks has a specific format of insurance coverage provided, the peculiarity of which is that, due to the multiplicity of possible risks of a construction object, the insurance contract for a construction object does not contain a list of them, but on the contrary contains a list of cases, the damage from which is not is subject to reimbursement by the insurer.

In international practice, insurance coverage does not cover losses [8]:

- caused by defects and errors arising in the design and manufacture of materials;

- as a result of gross negligence of the policyholder and deliberate damage caused by him or his representative;

- as a result of extraordinary and military events, the arrest of property by a court decision;

- as a result of strikes or mutiny;

- damage caused by exposure to nuclear energy.

Thus, insurance can cover all civil and industrial construction projects, with the exception of those listed in the list.

\section{Results and Discussions}

Currently, providing effective insurance coverage against all risks that may occur during construction and installation work at a construction site, in the Russian and international practice of insurance of construction risks, the insurance standard provides for the use of two types of insurance - CAR (Contractor`s All Risks) and EAR (Engineering All Risks) [9].

CAR insurance provides effective protection against all risks of all participants in the investment and construction process from possible losses. This type of insurance also allows you to reduce the construction estimate, since the provided insurance premium is always lower than the risk premium included in the construction estimate. This type of insurance is most in demand all over the world. As a rule, for the construction of state and municipal facilities, the requirement for the conclusion of CAR insurance is mandatory. More and more often, for obvious reasons, developers, credit organizations, architects, and consulting firms insist on the conclusion of this type of insurance contract [10].

EAR construction and erection risks insurance provides for the insurance of all possible risks during the installation of machines, mechanisms, and the erection of steel structures. In this case, the policyholders may be: the manufacturer or supplier of the installation object; firms directly performing installation; customer; credit organizations. The insurance coverage provided by the insurance contract applies to the territory specified in the insurance contract, usually a construction site. 
The period of validity of the insurance contract is determined by the participants and covers the time interval from the moment the equipment (building materials) is unloaded on the construction site specified in the contract and until the acceptance or commissioning of the construction facility. The most common drawback is the designation by the beginning of activities in the insurance contract of the moment the contract enters into force, the agreement is valid from the date of its conclusion or the transfer of the insurance premium. The validity of insurance for construction and installation works is determined from the moment of commencement of work and is valid until the delivery of the object. If the construction contract provides for post-launch warranty service, the insurance coverage can be extended for this period, for example, one year, after the acceptance of the object. Maintenance risk insurance can be standard - it covers only damage caused during the maintenance of equipment, or extended, in addition to the standard risk coverage, insurance for losses caused by errors in the process of construction work [11].

Risk management primarily involves preventing the possibility of their occurrence (avoiding risk) and mitigating the consequences throughout the entire life cycle of the project (insurance against risk, transferring risk to the partner who is able to manage it more effectively). As practice shows, it is impossible to keep all risk factors under control. One of the approaches to managing and limiting the impact of risks in construction, caused by external and internal factors, is "the creation of information systems to monitor various risk factors - from changes in federal legislation to incorrect performance of the task" [5].

Reducing risks during the implementation of an investment project can be ensured:

- creation of a reserve fund for unforeseen expenses associated with design errors, nonfulfillment of financial obligations on the part of partners, etc .;

- the creation of a reserve of time in case of an increase in the timing of certain types of construction work;

- a decrease in construction volumes due to production and non-production losses, etc.

The size of the reserve fund for unforeseen expenses is determined by the customer in accordance with the norms stipulated by the Urban Planning Codes of the Russian Federation: "no more than $2 \%$ - for non-production capital construction projects; no more than $3 \%$ percent - for capital construction facilities for industrial purposes and linear facilities; no more than $10 \%$ - for unique, especially dangerous and technically complex capital construction projects ". [12]

In addition, the amount of the insured amount, by agreement of the parties, can be paid separately for construction and installation works, construction and installation equipment and the cost of purchased or refurbished technical equipment and machinery in accordance with the estimated cost of the construction object. Construction companies increasingly include in the field of insurance coverage expensive high-performance equipment, the repair and maintenance of which require considerable financial costs.

\section{Conclusions}

The main part of modern green buildings are office buildings, the greatest contribution to their economic efficiency is made by an increase in labor productivity, which, according to G. Katz's calculations, accounts for, on average, $75 \%$ of the total economic effect obtained during the operation of the "green" production he studied. buildings. the main factor in the growth of labor productivity is the decrease in the number of days missed due to illness and without a valid reason. The difference in geographic and economic conditions does not allow extrapolating foreign estimates of the effectiveness of "green" buildings on the Russian construction market. Other reasons for the slow introduction of green technologies into the practice of Russian construction companies include the conservatism of the participants in the real estate market, insufficient information about available technologies, 
as well as the lack of specialized specialists at all stages, including the development of the concept and design of "green" buildings.

\section{References}

1. Civil Code of the Russian Federation, 742

2. Town planning code of the Russian Federation, 481

3. Tax Code of the Russian Federation, 25(4), 263

4. Federal Law No. 39-FZ dated 25.02. 1999 "On investment activities in the Russian Federation carried out in the form of capital investments"

5. J. Pinkse, A. Kolk, International Business and Global Climate Change, Routledge, (2009)

6. $\quad$ Ernst \& Young Business Risks Report (2010)

7. Common Carbon Metric for measuring Energy Use \& Reporting Greenhouse Gas Emissions from building operations, UNEP SBCI (2009)

8. Green IT: Why Mid-size Companies are investing now, Info-Tech Research Group (2009)

9. Energy and Small and Medium Enterprise, US Agency for International Development (2001)

10. C. Mines, How Tech Will Be Critical to Corporate Sustainability in 2011 (2011)

11. The Business Value of "Green" Document Management Solutions, White paper, IDC (2010)

12. Climate change: global study 2010, Synovate Research Group (2010) 